San Jose State University

SJSU ScholarWorks

Master's Theses

Master's Theses and Graduate Research

1993

\title{
Parents' perceptions of the impact of an occupational therapy early intervention home program on their roles and use of time
}

Justine Alcocer

San Jose State University

Follow this and additional works at: https://scholarworks.sjsu.edu/etd_theses

\section{Recommended Citation}

Alcocer, Justine, "Parents' perceptions of the impact of an occupational therapy early intervention home program on their roles and use of time" (1993). Master's Theses. 666.

DOI: https://doi.org/10.31979/etd.sp8g-n28q

https://scholarworks.sjsu.edu/etd_theses/666

This Thesis is brought to you for free and open access by the Master's Theses and Graduate Research at SJSU ScholarWorks. It has been accepted for inclusion in Master's Theses by an authorized administrator of SJSU ScholarWorks. For more information, please contact scholarworks@sjsu.edu. 


\section{INFORMATION TO USERS}

This manuscript has been reproduced from the microfilm master. UMI films the text directly from the original or copy submitted. Thus, some thesis and dissertation copies are in typewriter face, while others may be from any type of computer printer.

The quality of this reproduction is dependent upon the quality of the copy submitted. Broken or indistinct print, colored or poor quality illustrations and photographs, print bleedthrough, substandard margins, and improper alignment can adversely affect reproduction.

In the unlikely event that the author did not send UMI a complete manuscript and there are missing pages, these will be noted. Also, if unauthorized copyright material had to be removed, a note will indicate the deletion.

Oversize materials (e.g., maps, drawings, charts) are reproduced by sectioning the original, beginning at the upper left-hand corner and continuing from left to right in equal sections with small overlaps. Each original is also photographed in one exposure and is included in reduced form at the back of the book.

Photographs included in the original manuscript have been reproduced xerographically in this copy. Higher quality $6 " \times$ " 9 " black and white photographic prints are available for any photographs or illustrations appearing in this copy for an additional charge. Contact UMI directly to order.

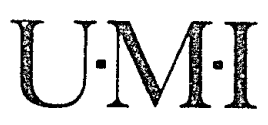



Parents' perceptions of the impact of an occupational therapy early intervention home program on their roles and use of time

\author{
Alcocer, Justine, M.S.
}

San Jose State University, 1993 



\title{
PARENTS' PERCEPTIOÑS OF THE IMPACT OF AN OCCUPATIONAL THERAPY EARLY INTERVENTION HOME PROGRAM ON THEIR ROLES AND USE OF TIME
}

\author{
A Thesis \\ Presented to \\ The Faculty of the Department of Occupational Therapy \\ San Jose State University
}

In Partial Fulfillment

of the Requirements for the Degree Master of Science

by

Justine Alcocer

December, 1993 
(c) 1993

Justine Alcocer

ALL RIGHTS RESERVED 
APPROVED FOR THE DEPARTMENT OF OCCUPATIONAL THERAPY

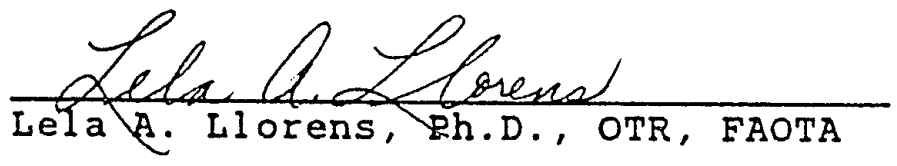

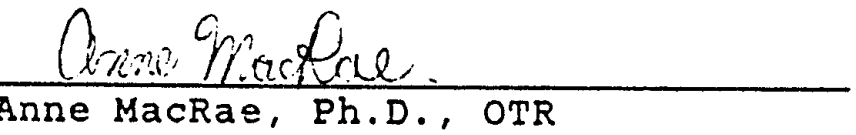

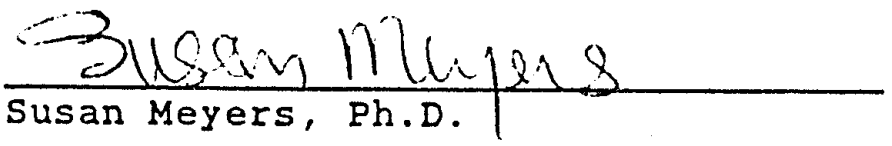

APPROVED FOR THE UNIVERSITY

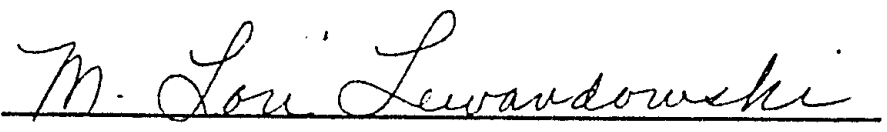




\section{ABSTRACT}

\section{PARENTS' PERCEPTIONS OF THE IMPACT OF AN OCCUPATIONAL THERAPY EARLY INTERVENTION HOME PROGRAM ON THEIR ROLES AND USE OF TIME \\ by Justine Alcocer}

This thesis addressed parents' perspectives of changes in their life roles and use of time, as a result of receiving home-based occupational therapy for their infant or toddler with developmental delays. In addition, the caregivers' perceptions of their current roles and time use were examined.

Six participants completed activity configurations and semistructured interviews. The transcribed interviews were qualitatively analyzed, and synthesized to identify recurring themes. The themes included the balancing act, sacrifices, establishing and relinquishing control, enabling families, to each his own role, belonging vs. isolation, and teamwork.

The recurring themes were used to answer the research questions and discuss the implications for occupational therapy practice and research. The results give preliminary support to the role of occupational therapists of assisting families to achieve satisfaction in their roles and time use, utilizing a consultative and family-centered approach, reciprocal communication, modeling, and education. 


\section{ACKNOWLEDGMENTS}

I welcome the opportunity to acknowledge the contribution made by the following people to the completion of this study:

My thesis advisor, Lela A. Llorens, Ph.D., OTR, FAOTA, Chairperson, Department of Occupational Therapy, San Jose State University.

My first thesis reader, Anne MacRae, Ph.D., OTR, Associate Professor, Department of Occupational Therapy, San Jose state University.

My second thesis reader, Susan Meyers, Ph.D., Professor, Division of Special Education and Rehabilitative Services, San Jose state University.

Finally, a heartfelt thank you to the Agency for Infant Development, Fremont, California, and the parents who openly shared their lives and experiences with me. 
TABLE OF CONTENTS

CHAPTER 1: INTRODUCTION 1

Purpose 1

Statement of the Problem 1

Research Questions 2

Definitions 2

Assumptions 6

Limitations 6

Significance of the study $\quad 7$

CHAPTER 2: REVIEW OF THE LITERATURE 11

Evolution of the Parent's Role in 11

Early Intervention

The Family-Centered Approach 15

Studies Depicting Parents' Role and 16

Time Demands

Potential Positive Impact of 20

Occupational Therapy

Environmental Factors Contributing 21

to Roles and Time Use

Occupational Behavior and General 21

Systems Theory

Summary 24

CHAPTER 3: DESIGN AND METHODOLOGY 26

$\begin{array}{ll}\text { Questions } & 26\end{array}$

$\begin{array}{ll}\text { Sample } & 27\end{array}$

Instruments $\quad 28$

$\begin{array}{ll}\text { Procedure } & 29\end{array}$ 
Data Analysis

CHAPTER 4: DATA AND RESULTS 32

$\begin{array}{ll}\text { Participants } & 32\end{array}$

Work 34

Childcare $\quad 35$

Leisure/Play $\quad 36$

Self-Maintenance 36

Sleep/Rest $\quad 37$

Participants' Description of 37

Their Children

Recognition of Problem and 38

Securing Assistance

Parent's Perception of the Occupational 40

Therapy Home Program

Parent's Role in Early Intervention 41

Role and Time Use 42

$\begin{array}{ll}\text { Themes Identified } & 48\end{array}$

Answers to Research Questions 60

CHAPTER 5: DISCUSSION WITH IMPLICATIONS 68

Themes and the Literature 68

Discussion of Research Questions 69

Relevance to Systems Theory and 72

Occupational Behavior

Relevance to the Family-Centered Approach 74

Implications for Occupational Therapists 76

$\begin{array}{ll}\text { Suggestions for Future Research } & 78\end{array}$

$\begin{array}{ll}\text { REFERENCES } & 80\end{array}$ 
APPENDIX A: ACTIVITY CONFIGURATION 86

APPENDIX B: INTERVIEW GUIDELINE 88

APPENDIX C: INTRODUCTION LETTER TO SUBJECT 91

APPENDIX D: CONSENT FORM 93

APPENDIX E: EXPERIMENTAL BILL OF RIGHTS 


\section{LIST OF TABLE}

Table 1: Summary of subjects 
CHAPTER 1

\section{INTRODUCTION}

\section{Purpose}

The purpose of this study was to investigate parents' perspectives of changes, if any, in their life roles and use of time, as a result of receiving home-based occupational therapy for their infant or toddler with developmental delays. In addition, the caregivers' perceptions of their current roles and time use were explored.

\section{Statement of the Problem}

The policies affecting early intervention and the growth of home-based therapy are advancing more rapidly than research can explore it (Short-DeGraff, 1987). While research evidence generally supports the positive influence of early intervention programs on the developmentally delayed child's mental and physical development (Haber, 1991; Ross, 1984), little information is known about the effect on the child's family (Hinojosa \& Anderson, 1991; Roberts, Wasik, Casto \& Ramsey, 1991;

Shonkoff \& Hauser-Cram, 1987). Particularly scarce is information on the specific impact of occupational therapy, or the impact of any type of early intervention, on family roles and use of time (Roberts, et al., 1991). As variances 
and interactions between occupational therapy interventions and family characteristics cannot easily be controlled, or measured quantitatively, a fuller, more insightful picture of the impact of an occupational therapy homeprogram can best be obtained from parents' narrative accounts of their unique experiences.

Research Questions

The following questions were answered by this study:

(1) How does the parent of a child with developmental delays, who is participating in an occupational therapy early intervention home program, perceive his or her present time use and roles?

(2) How does the parent of a child with developmental delays perceive the impact of an occupational therapy early intervention home program on his or her life roles?

(3) How does the parent of a child with developmental delays perceive the impact of an occupational therapy early intervention home program on his or her time use?

\section{Definitions}

\section{Developmental Delay}

\section{Conceptual Definition}

Each state is given the authority to define

"developmental delay." Generally, it can refer to three 
conditions, or combination of factors (Hanft, 1988). First are children with genetic or biological conditions associated with developmental delay, such as Down syndrome or cerebral palsy. This could also include "low incidence" disabilities, which are defined as visual, hearing, or orthopedic impairments.

Second are those with medical problems that indicate a risk for developmental delay, such as seizures, low birth weight, or premature birth. Third are those who are subject to environmental risks, such as neglect or parental drug abuse.

operational Definition

The research subject's child, who is receiving occupational therapy services, will have at least a one month delay, as demonstrated by any evaluation means that are used at the agency that is serving the child, in two or more of the following areas: gross motor, fine motor, cognitive, receptive language, expressive language, social, or self-help skills.

\section{Occupational Therapy Early Intervention Home Program} Conceptual Definition

Early intervention encompasses a wide range of services provided for families of young children, from birth to three years of age, who have, or are at risk for, developmental delay. Occupational therapy is included in 
the Public Law 99-457 definition of early intervention as one of ten primary developmental services. The role of the occupational therapist may vary from agency to agency. The services may be based on a range of intervention models, and may take place at the child's home, commonly performed for infants who are medically fragile or under a year old. Operational Definition

In this study, the home program is one in which an occupational therapist (OTR) provides direct services for a child under the age of three in his or her home. The therapy may be child and/or family focused, and may include indirect services. The caregivers' children in this study were not receiving any other direct therapeutic services, such as physical or speech therapy.

\section{Role}

\section{Conceptual Definition}

Kielhofner (1992, p. 158) defined roles as "images that persons hold about the positions they occupy in various social groups and of the obligations that go along with those positions." One may engage in multiple roles simultaneously, or find that one role carries obligations in all performance areas: work, leisure/play, selfmaintenance, and rest (Christiansen, 1991). 


\section{Operational Definition}

Possible role status labels of mother/father, husband/wife, other family member, friend, worker, hobbyist, volunteer, religious participant are suggested to subjects on the activity configuration (Appendix A). Parents' perceived roles may include these, as well as their own labels and descriptions of the occupational and familial positions that they hold, each role containing a unique set of expectations, responsibilities and rewards.

\section{Time Use}

\section{Conceptual Definition}

Time use refers to how one organizes and spends time, as determined by one's roles, culture, values, interests, and goals (Kielhofner, 1977).

Operational Definition

Time use will be expressed as subjects' accounts of the sequence, the time of day, and the length of time that they spend performing activities within the occupational areas of work, play/leisure, sleep/rest, and selfmaintenance on a tyoical weekday., Time use will be expressed both verbally and visually, with the aid of an activity configuration, as parents' perceptions. Thus, actual time figures may not be exact, or inclusive of all activities performed in a day. 


\begin{abstract}
Assumptions
Underlying this study is the assumption that occupational therapists recognize the importance for parental role balance and role satisfaction, and its impact on a healthy interaction between child and parent. It is assumed that there may be some parents who will be very involved in an early intervention home program for their child, or whose life will have been affected by occupational therapy, and others who may not be as involved or affected. Each life story is valuable to the understanding of the impact of occupational therapy early intervention on the family.

The trustworthiness of this study relies on the assumption that interviewees will speak truthfully, recall events accurately, and be able to relay explicit, meaningful responses. It is also assumed that the researcher's analysis reflects the intended meaning of the data with clear recognition of any biases.
\end{abstract}

\title{
Limitations
}

The size of the study sample' and the nature of qualitative research does not lend itself to results that can be generalized. The population will be too small to represent the many combinations of factors that can influence the impact of an occupational therapy home 
program. Potential variables which cannot be equally represented include severity of the child's developmental delay, the quality of the caregivers parenting skills and parent-child interactions at program entry, awareness and utilization of community resources prior to intervention, length of time in the home program, and the age of the child at the time of intervention. Though the results will not be generalized, they may suggest themes or trends that can be explored further.

The results are limited by the subjects' responses and the researcher's ability to interpret their intended meaning. The subject's responses may be compromised by the open-interview method used. Parents may be reluctant to be completely honest, especially if their views of occupational therapy are negative. In discussing events and feelings that took place in the past, there is always the danger of distorted memories. Parents may also have difficulty making a connection between the occupational therapy early intervention program and their personal roles and use of time in the present.

\section{Significance of the study}

The impact of early intervention on the family is a topic that has received increased attention since the enactment of the 1987 Amendments to the Education for all Handicapped Children Act (Public Law 99-457), and its 
recent revision in 1991, entitled the Individuals with Disabilities Education Act (IDEA). This important passage of legislature accentuates family involvement in the planning and implementation of occupational therapy treatment for children under the age of three.

As a result, this decade is likely to witness a considerable increase in family-focused occupational therapy home visiting services (Schaaf \& Mulrooney, 1989). The proportion of occupational therapists who serve infants and young children has increased dramatically in recent years (Lawlor \& Henderson, 1989), and the most common problem identified (47.5\%) as the reason for referral to occupational therapy was developmental delay.

The American Occupational Therapy Association [AOTA] supports a family-focused approach to early intervention, in which "occupational therapy personnel help parents to find satisfaction in their occupational roles as providers and caregivers and to increase their skills in managing the stresses of daily living and child care" (Dunn, Campbell, Oetter, Hall \& Berger, 1988, p. 793). To Eulfill this position, therapeutic intervention for infants and toddlers will likely include goals directed specifically toward their parents (Anderson \& Hinojosa, 1984).

This family focused intervention has the potential for creating role changes among family members and shifts in 
their use of time (Christiansen, 1991). With this emphasis on family participation, parents may be called upon to increase the amount of their time spent on child-related activities, and to adjust their life roles, an issue over which both parents and professionals have expressed concern (Rodger, 1986; Turnbull \& Turnbul1, 1982). Information on how these changes may subjectively affect primary caregivers is important, as parental attitudes toward therapy, whether positive or negative, can likewise have a positive or negative effect on the child (Humphrey, 1989; Anderson \& Hinojosa, 1984).

Furthermore, in keeping with an occupational behavior frame of reference, in which role balance and role satisfaction are significant for human functioning, therapists must be either be able to provide guidance in time management and role balance, or be prepared to accept a parent's decision to assume roles that might be deemed inappropriate by the professional. Bricker and Casuso (1979) assert that professionals should not question whether or not the family should be involved in early intervention for their child, but how they can be most effectively involved. The research team of shonkoff, Hauser-Cram, Krauss and Upshur (1988) have claimed that for effective parent involvement, it is important to ask, "What types of early intervention services are the most effective for what types of children and families?" 
Parents' feedback on the impact of their occupational therapy home program can help to answer this question, and other previously mentioned ethical dilemmas, by illustrating the types of roles and time commitments that families are required, willing, and able to undertake, under a variety of circumstances. Occupational therapists are in a versatile and key position to examine these issues and to share the findings with colleagues in both the education and health care communities. 
CHAPTER 2

LITERATURE REVIEW

Evolution of the Farent's Role in Early Intervention

The general attitudes and beliefs of medical and educational professionals, regarding the role of parents in early intervention, have evolved through three general stages since World War II (Bazyk, 1989). These stages could be described as "parent-as-outsider," "parent-astherapist," and, most recently, "the parent/therapist collaboration." Occupational therapists have been involved with young children since the 1950s. Most of the early programs included children who were diagnosed with biological impairments. At this time, parents were not thought to be appropriate leaders in the care of their "handicapped" or "retarded" children. Doctors, teachers, and other service providers were thought to be the most capable individuals to define the family's needs and to choose appropriate intervention (Roberts, et al, 1991). Thus, the parent was often viewed as an outsider.

Throughout the 1960 s and 1970s, many societal changes took place which were to shape our early intervention programs. Parents came to be viewed as more of a solution to their child's deficits, than as a contributor (Poyadue, 1988; Roberts, et al, 1991). The advance of medical 
technology increased the survival rates of many high-risk newborns (Mather \& Weinstein, 1988), increasing the number of young children who would need special services. With the trends of deinstitutionalization, rising medical costs, and the decline of health care workers available for service provision, parents were more likely to take on roles associated with special education and health care in their own home. Enlisting parents to participate in their child's therapy became not only a popular philosophy, but economically necessary.

Important Federal bills were passed in support of these changes. By 1975, the Education for all Handicapped Children Act [EHA] mandated occupational therapy as a support service to assist the handicapped child in benefiting from education. The act created new expectations for parents to be part of the decision-making process, to be planners, coordinators, and advocates for their school-aged child's education (Rodger, 1986).

Occupational therapists met the trend toward family involvement with a role shift, from an emphasis on direct child service, to an emphasis on indirect service through family training (Short-Degraff, 1987). The therapist typically developed a therapeutic program, and instructed the parents, or primary caregiver, to carry it out at home (Bazyk, 1989). Parents were often viewed as teachers and 
therapists, and those who did not follow through on activities at home were considered noncompliant (Allen \& Hudd, 1987 Bazyk, 1989).

Only in the last 10 years have children begun to enter comprehensive early intervention programs shortly after birth (Mather \& Weinstein, 1988). With the passage of Public Law (P. L.) 99-457, which amended the EHA, occupational therapy was considered a primary service for developmentally delayed infants and toddlers, not just a support for the education system. This allowed an increasing number of occupational therapists to work in the child's home, in addition to a school setting.

The Handicapped Infants and Toddlers Program (Part $H$ of P. L. 99-457) also contained numerous provisions designed to facilitate family involvement in early intervention for their children. This was interpreted by many in the field of early intervention (Allen \& Hudd, 1987; Arango, 1989; Hanft, 1988; Roberts et al, 1991) to mean that parents were to be permitted, if not encouraged, to participate in their child's therapy and education by taking on such roles as educational decision maker, therapist, child advocate, case manager, program evaluator, problem solver, and member of the state Interagency Coordinating Council, to name a few possibilities. As one parent of child with a disability stated (Arango, 1989, p. 3-9), "Like Bartholomew Cubbins, we wear thousands of 
hats."

While some people labeled these changes as progress, opponents saw them as an invasion of privacy, a threat to the family's ability to function independently, and a possible means of placing excessive expectation and responsibility on the caregivers (McGonigel \& Garland, 1988; Short-DeGraff, 1987). Some feared that by contributing to the "number of hats," occupational therapists may have been potentially creating a negative impact on parents' roles and daily routines (Rodger, 1986; Turnbull \& Turnbull, 1982).

In the latest evolutionary step of early intervention service provision, the Education of the Handicapped Act was renamed in Public Law $101-476$ as the Individuals with Disabilities Education Act (IDEA). Though much of the content of the EHA was retained, the terminology in the IDEA, and in the IDEA Amendments of 1991 (Public Law 102119), was changed to reflect the view that people come before their disabilities. At the same time, the original intention of collaborative parent involvement became clear. Rather than fitting all families into a mold, policy makers and service providers today are encouraging collaboration with parents, to discuss with families individually the roles that they would like to take in early intervention. 
The Family-Centered Approach

One of the family provisions required by the IDEA is an Individualized Family service Plan (IFSP), described in Section 677. The IFSP is a contract which includes an outline of the family's strengths, needs, desired outcomes, and methods in which services will be provided. More important than the written product itself is the process of interaction, and collaboration between families and professionals that is necessary to develop and implement the IFSP (MCGonigel \& Johnson, 1991).

The assurance of role satisfaction and a balance of time and roles is an important part of this collaboration. Bazyk (1989) stated that professionals should value occupational role develonment in families, with a balance of work, play, and rest. All aspects of the parent's role as parents should be valued, not only as a person responsible for their child's health care needs, but also their need for time spent in social interactions, nonstructured kinds of play, and rest.

A family centered approach, which respects parents' diverse roles, values, and coping styles will necessitate programs that enable and empower families (McGonigel, 1991). To enable families is to create opportunities for them to utilize their present abilities and to acquire new competencies as necessary to meet the needs of their 
children (Dunst, Trivette, \& Deal, 1988). Empowering families involves interacting with parents in such a way that they maintain a sense of control over their life and attribute positive changes that result from early intervention to their own strengths, abilities and actions (Dunst, Trivette, et al., 1988). Though these principles are now widely endorsed (McGonigel, 1991), there has been little feedback, reflected in the literature, as to whether this collaborative approach is being utilized successfully between occupational therapists and families in early intervention home programs.

Studies Depicting Parents' Role and Time Demands

One of the few critical qualitative studies on the impact of a home program is Hinojosa's case study which looks (Hinojosa, 1990; Hinojosa \& Anderson, 1991) at how eight mothers of preschool aged children with cerebral palsy perceive occupational and physical therapists and their influence on family life. Each of these women were married, had at least two children, and lived in low to middle class neighborhoods in New York. Following intense interviews with the mothers, conducted between 1987 and 1988, the researcher identified themes that were important to the participants and their families.

An important discovery emerged that although each of 
the mothers had attempted to implement a therapistdeveloped home therapy program at one time, she was no longer doing so, due to lack of time, energy, or confidence. The mothers described their days as being very busy, with many activities centered on the child with cerebral palsy.

The time demands experienced by a family with a disabled child have been noted by several other authors as well (Friedrich \& Friedrich, 1981; Johnson \& Dietz, 1985; Lucca \& Settles, 1981; Smith, 1986). A common conclusion among these authors was that families of child with a disability spend more time doing childcare and less time doing housework than the average family. It was also speculated that home therapy programs might influence the amount of leisure and interactive behavior in which a caregiver is involved. The premise being, that while providing care for the developmentally delayed child, the parent may need to push aside other enjoyable activities. Occupational therapists, Johnson and Dietz (1985), investigated time usage further and noted that mothers of children with disabilities do not have the same freedom of role choice as do mothers of nonhandicapped children. They observed that responsibility for caring for a disabled child is often made heavier by tasks given to parents by specialists, like physical or occupational therapists, and by the need to transport the child to various settings for 
specialized medical care.

In Hinojosa's study, the mothers perceived that the presence of a child with special needs altered the roles, responsibilities, and activities of every member of the family. When possible, they maintained their normal family rituals and routines, but would adapt their roles, interactions, and activities to incorporate the child as an integral family member. The home therapy program itself did not appear to have as great an impact on roles and time use, considering that the mothers did not feel that they were required to precisely follow a home program as suggested by the visiting therapist. Instead, they had learned to select or adapt interventions that conformed to their life-styles, with minimal disruption of their own daily routines.

Though the parents in the studies mentioned above generally indicated that having a child with a disability resulted in increased childcare responsibilities and changes in the family routine, their satisfaction with such changes is uncertain, and may have varied. Some parents have noted that, because of their expanded role in therapy for their infants with delays, they felt more confident and competent in their role as parents (Moxley-Haegert \& Serbin, 1983). Hinojosa (1990) noted that the eight mothers whom he interviewed did not seem depressed or 
chronically fatigued, but appeared to be satisfied with their role as primary care provider, despite their additional responsibilities.

A Swedish research team (von Wendt, Ekenberg, Dagis \& Janlert, 1984) studied parental attitudes toward having a highly active role in occupational therapy and physiotherapy, including taking responsibility for a daily training program. The few complaints voiced by the parents were mostly in response to infrequent contact with the therapist, and partly in response to lack of time, or having too many tasks to do. The authors' overall sense was that most parents were adjusting to the home program well.

While some parents welcome the opportunity to take on new roles and therapist-like responsibilities, others may not want to do so, or may not feel ready for the responsibility (Anderson \& Hinojosa, 1984). Some parents of children who have disabilities have reported dissatisfaction with their roles and daily schedules. Mothers of children with cerebral palsy have reported feelings of emotional and physical fatigue from the day-to-day care they must provide (Joyce, singer, \& Isralowitz, 1983). Though less studied, fathers of children with disabilities may have unique concerns, such as feelings of inadequacy in fulfilling traditional parental roles (Barber, Turnbull, Behr \& Kerns, 1989). 


\section{Potential Positive Impact of Occupational Therapy}

The potential burden that a home program can create is evident in the literature just described. However, therapists can also make a positive impact on family roles and use of time. Occupational therapy home visitors are in a position to empower families, to relieve some of their stress, to lend social support, and, consequently, to help caregivers increase their role satisfaction, not only in the context of therapy and childcare, but in areas such as personal self-care and leisure (Dunst \& Trivette, 1987; Humphrey, 1989; Schlaff, 1991).

At least two studies (Crnic, Greenberg, Ragozin, Robinson \& Basham, 1983; Crnic, Greenberg, Robinson \& Ragozin,1984) have suggested that stress level and social support are predictors of subjective maternal satisfaction with their lives and parenting role. Thus, an early intervention home program, when viewed by parents as a stress reliever and source of social support, could have a positive impact on his or her role satisfaction. For this purpose, a home program may especially be of benefit to the family with many time commitments, as it is presumably more adaptable to the family's schedule than a center-based program. 
Environmental Factors Contributing to Roles and Time Use

Outside of the occupational therapy home program, and the child who is being served, there are other factors that contribute to parents' roles and use of time that cannot be overlooked. Family size, marital and employment status, income level, family support system, and community resources, are just a few such variables which may result in a family structure that is incongruent with the time demands and role expectations of some family-oriented therapists (Short-DeGraff, 1987; Zisserman, 1981).

For example, it has been found that single working mothers already spend less time in personal care, household tasks and physical childcare, such as feeding and bathing the children, than married or non-employed mothers, according to one study (Sanik \& Mauldin, 1986). The logistics of caring for a child with special needs, in addition to being single and employed, can be much more difficult.

Occupational Behavior and General Systems Theory

Occupational therapists often subscribe to developmental and sensorimotor frames of reference in treating infants and children (Lawlor \& Henderson, 1989). . Occupational behavior was the least essential frame of 
reference selected by pediatric therapists in Lawlor \& Henderson's survey (1989). However, understanding the themes of occupational behavior and its philosophical consociate, general systems theory, can be an asset to serving young children in the context of their family, as mandated today.

General systems theory can be described as a means of organizing information, a way of looking at phenomena from several perspectives simultaneously. Attention was drawn to the systems concept by von Bertanlanffy (cited in Ackoff, 1974), and related to occupational therapy largely in the works of Reilly (1974) and Kielhofner and Burke (1980). A system can be described as a whole consisting of interdependent components, such as a human being consisting of biological and psychological components.

Systems are concurrently components, or subsystems, of even larger systems. For example, a person is part of a family, which is part of a society, and so on. Thus, a hierarchy of subsystems within systems develops in which higher order systems govern, yet are limited by, lower order systems. A person may act according to the greater needs of the family, for instance, but is limited by his or her individual abilities.

The hierarchial and interdependent nature of systems leads to the important principle that a change in any system level has altercations in the system whole. 
are discovered by taking a look at objects and concepts as part of larger wholes. For instance, parents' organization of time spent on occupational therapy related activities can be viewed in the context of their individual roles, within the greater family environment and society at large.

Occupational behavior is a biosocial approach based upon the systems view that individuals cannot be separated from the environment. The major themes of this frame of reference, as described by Reilly (cited in shannon, 1988), are roles, temporal adaptation, and competency.

Christiansen and Baum (1991) present a systems view of these themes within their person-performance-environment framework. Within this framework, roles are the highest order of performance, followed by tasks and activities. Roles are behavior expectations that are derived in the context of larger societal systems.

According to the requirements of their personal roles, individuals then organize the sequence and time length of their daily tasks. Tasks can be viewed as specific activities, which are, in turn, limited by the individual's competency, or mental and physical capacity to perform the activities. Role dysfunction, according to the occupational behavior frame of reference (cited in shannon, 1988), is present when persons cannot perform roles to satisfaction, have deficits in skills or abilities, 
conflicting demands of multiple roles, or unclear role expectations.

\section{Summary}

Over the past 20 years, occupational therapists have placed increasing value on the role that parents play in their children's development and, consequently, have promoted parent participation as an integral part of any early intervention program (Moersch, 1989). A family centered approach, which evolved with recent education legislature, emphasizes a collaboration between parents and professionals, a respect for families' current roles and schedules, and the use of therapeutic styles that enable and empower families.

The majority of the studies on parent roles and time use are actually investigating the impact that a disabled child has on his or her family, rather than the impact of a home program. Most studies do not differentiate developmental delay from other diagnoses in their population sample. Thus, many of the studies discussed here may be based on families that care for a child with significant needs, or who are receiving multiple therapy services.

What can be concluded from the review of the literature is that occupational therapy home programs have 
the potential of making a positive or negative impact on parents' perceptions of their roles and use of time. However, the specific effect of occupational therapy is difficult to interpret when it cannot be separated from other interventions (Gorga, 1989), or from the complex interaction of human factors. Thus, it is useful to approach the study of parents' perceptions of the impact of early intervention home program from a systems and occupational behavior perspective. 
CHAPTER 3

DESIGN AND METHODOLOGY

The purpose of this study was to investigate parents' perspectives of changes, if any, in their life roles and use of time, as a result of receiving home-based occupational therapy for their infant or toddler with developmental delays. In addition, the caregivers' current use of time, and satisfaction of roles and time use were explored. Data were collected by individual in-depth interviews, using qualitative case study methodology.

\section{Questions}

This study was designed to answer the following questions :

(I) How does the parent of a child with developmental delays, who is participating in an occupational therapy early intervention home program, perceive his or her present time use and roles?

(2) How does the parent of a child with developmental delays perceive the impact of the occupational therapy early intervention home program on his or her life roles? (3) How does the parent of a child with developmental delays perceive the impact of the occupational therapy early intervention home program on his or her time use? 
Sample

Subjects for the study were six adults (three married couples), all legal parents of children who are currently visited by an occupational therapist for home-based early intervention services. The subjects also met the criteria of having a child who fits the following description: (1) Is less than thirty-six months old. (2) Has been determined by any prior developmental assessment to have a developmental delay [in at least one of the following areas: gross motor, fine motor, cognitive, language, social, or self-help skills], (3) Is currently only receiving direct therapeutic services through a visiting occupational therapist. Table 1 summarizes the characteristics of the six subjects.

The participants were selected on a first-come, firstserve volunteer basis. They are being served by one of two occupational therapists, including the researcher, through an early intervention agency in Alameda County.

The rationale behind the subject criteria was to limit the investigation to a narrow subset of people served by occupational therapy, who may have distinct qualities that have not been detected in the heterogeneous subject pools of so many early intervention studies. Due to the scarcity of this sample population, only five children were found who met the research criteria, from among twelve early 
intervention agencies contacted in the Bay Area. Of these ten potential subjects (two parents per child), six agreed to participate in the study.

\section{Instruments}

The two instruments used for the study were an activity configuration and an interview guideline (Appendices $A$ and $B$ ). The activity configuration used in this study was adapted from one used at San Jose state University. It consists of a variation of an activity clock, as described by cynkin (1979), in which a schematic drawing of a 24-hour clock is shaded in to denote how much time the subject spends daily on his or her occupational performance areas, such as work, self-care, sleep, leisure. In addition, several examples of life roles were listed below the clock, for the participant to select as being significant in his or her life. The purpose of the activity configuration was to form a visual baseline of the roles which the parent assumes and how his or her time is divided among those roles on a typical weekday.

The researcher developed the interview guideline based on clinical experience and review of the literature. Hinojosa (1990) provided an interview guideline from which many questions were adopted. The general areas to be queried were determined according to their appropriateness or relevancy to the research questions. Slight revisions 
were made following each interview.

\section{Procedure}

Interviews were scheduled on an ongoing basis, as the parents volunteered by phone call or face-to-face contact with the researcher. Prior to the interview, the individuals were sent a letter requesting that they read and sign a consent form (Appendices $C$ and D), which outlined the research goals, general procedures, the participant's rights, and anticipated risks or benefits of the study. Concurrently, the subjects were asked to complete the activity configuration (Appendix A). Subjects were given at least seven days to review the consent form and the activity configuration, though some chose to complete these forms at the time of the interview.

Data were gathered by means of semi-structured interviews, using the interview outline developed by the researcher (Appendix B). Interviews were conducted at a time and location convenient to each participant. The subjects were interviewed separately, though their spouses often entered the room and occasionally joined in the conversation. Each interview was completed in one session and lasted from 20 to 100 minutes. With participants' prior knowledge and permission, the interviews were audio tape-recorded while the researcher was prepared to take 
notes. The subjects were able to look at their configuration during the interview as a frame of reference in answering questions about how his or her time is spent. The researcher allowed participants to continue conversation that was not directly or apparently relevant to the interview outline. An effort was made to conduct an interview with a normal conversational flow.

\section{Data Analysis}

Data were analyzed using qualitative methods, based on procedures described by Glaser and strauss (1967), Patton (1980), and Taylor and Bogdan (1984).

The recorded interviews were transcribed verbatim, each being its own case study. As each case study was read, the researcher's thoughts and inspirations were noted in the page margins. Notations were also made in the margins to designate separate topics of discussion, the initial "coding" of data. As new case studies were read, they were compared with the first, and topic headings changed if necessary to accommodate the new information.

The next two steps were a process of "cutting and sorting." The main coded topics of discussion became separate page headings. These categories generally paralleled the research questions. During the second reading, key phrases and themes were extracted from the raw data and transferred to the appropriately headed page. The 
third step was to break down the data further by developing coding categories for each of these key phrases and themes, within each major topic heading. These categories were developed in an attempt to also describe the meanings behind the data, and not merely the topic of discussion. As this step was completed with each case study, coding categories were modified to accommodate the new information. Data that were left out were examined and analysis refined.

With the data sorted into the coding categories, within a main topic of discussion, it was "reconstituted" to look for broader themes and relationships that may have occurred across all the interviews, as well as examples of responses that did not fit into any theme. The research questions were answered in terms of the themes. 
CHAPTER 4

DATA AND RESULTS

The interviews were all conducted at the homes of the participants, between the dates of July 17 and August 23, 1993. The participants were interviewed separately, though each participant also chose to be present for at least a portion of the time in which his or her spouse was being interviewed. Each interview was completed in one session, the shortest being 20 minutes, and the longest lasting an hour and 40 minutes.

\section{Participants}

The six participants consisted of three married couples living in Alameda county. The researcher is the ongoing OT home visitor for one couple, had provided an initial evaluation for another couple's child, and met the third couple for the first time at the interview. Thus, the researcher's level of familiarity differed with each participant.

A summary of the participants, their occupations, and the characteristics of their children is provided in Table 1. Pseudonyms are used for all participants' names. First names are in alphabetical sequence, to indicate subjects one through six, or $A-F$. Last names are in alphabetical 
Table 1

Summary of Subjects (Names have been changed)

\begin{tabular}{|c|c|}
\hline Parent Description & Child Description \\
\hline Abe Adams & *2 years old, male \\
\hline Professional- & *Adopted, only child \\
\hline management & *2.5 mo. premature, no diagnosis \\
\hline Brenda Adams & social, tantrums, verbal \\
\hline Professional-law & *Bimonthly OT visits, 1 year now \\
\hline Cindy Birch & *10 $1 / 2$ months, male \\
\hline Office work & *only child \\
\hline & *Agenesis of corpus collosum \\
\hline Dale Birch & *slow in motor and speech \\
\hline Small business & $\begin{array}{l}\text { Soon to have physical therapy } \\
\text { *Has had about } 5 \text { OT sessions }\end{array}$ \\
\hline Elsa Connor & * 14 months, male \\
\hline Homemaker & *Youngest of 5 children \\
\hline & $\begin{array}{l}\text { Older sibling has similar delay } \\
\text { *No diagnosis, motor problem }\end{array}$ \\
\hline $\begin{array}{l}\text { Frank Connor } \\
\text { Construction }\end{array}$ & $\begin{array}{l}\text { *Behind in eating, crawling, and } \\
\text { verbalizations. Good, quiet, }\end{array}$ \\
\hline related profession & *Weekly oT visits, for $3-4$ mo? \\
\hline
\end{tabular}


sequence to indicate which participants are married couples.

The ethnic makeup of the study population consisted of five Caucasian and one vietnamese participant (Cindy Birch). The parents appeared to be between the ages of 30 and 40 . All of the participants lived in homes that appeared to represent middle to upper middle income levels. The three males and two of the female participants had full time jobs outside of the home. One female worked exclusively in the home (Elsa Connor).

Work

Five of the six participants are engaged in full-time employment outside of the home. Elsa is the exception, as she works in the home, raising five children. Since she is not bringing in income, her husband, Frank, strongly views his work as an obligation, feeling the pressure to meet the family's financial needs. The other two men described some positive qualities about their jobs, but likewise tend to see their work role as a necessary responsibility of being the head provider of the family. Though the two working women also make substantial contributions to the household income, they did not express their work roles in terms of economic necessity. Brenda particularly emphasized work as a matter of personal choice. Cindy was 
also very committed to her job, where she spent most of her socializing time. While the Connors appeared to base more of their self-worth on parenting and volunteer work, it was evident that work in general was an invaluable source of self-esteem for everyone.

\section{Childcare}

The amount of time spent on childcare varied from parent to parent. Some parents included self-maintenance, play, and "therapy" in their definition of childcare, while others likened childcare more to feeding, dressing, and supervising the child. Factors related to time spent on childcare were the age and physical care needs of the child, the number of hours parents spent working outside the home, and the amount of support and childcare provided by the spouse, or other family member.

The Adamses spend the least amount of time on childcare, and their son seems to require less physical care than the other children with developmental delays. The childcare duties are divided fairly evenly between the spouses, with Abe spending one hour, and Brenda spending about two hours a day on childcare. Both parents also expressed a strong desire to spend more time with their child.

The Birches spend the most time on childcare for their child, with Dale spending three hours, and Cindy spending 
four and a half hours an evening with their son. Dale tends to take the responsibility of childcare when his wife is too tired to continue, or needs the time for other tasks.

Elsa Connor spends three and a half hours a day and her husband one and a half hours in the evening on childcare for their five children. The two older children, ages eight and ten, help a lot in the care of the younger children.

\section{Leisure/Play}

All participants indicated a desire for more leisure time. For one mother and all of the fathers, that included leisure time with their child. Two people indicated that they needed more time to themselves. In general, leisure was not a scheduled occupation, but rather came as a break at the end of work, self-maintenance, childcare, or other such responsibilities. Time available for leisure had perceivably decreased for all participants when they became parents, though some participants did make an effort to try to keep exercise, sports, hobbies, or adult friendships a part of their lives.

\section{Self-Maintenance}

Self-maintenance included tasks such as chores, 
eating, and grooming. Parents did not talk about their personal care needs very much. They were more apt to discuss household maintenance, with some parents not finding the time to do as much as they wanted, and others wishing that they could spend less time doing it.

\section{Sleep/Rest}

Most participants felt that they received an adequate amount of sleep for their physical needs, and would not increase or decrease the amount time spent in that area. Cindy was an exception; she reported feeling chronically tired and lacking in rest. She usually prevented herself and her child from going to sleep earlier in the evening in order to complete therapeutic activities. Elsa also changes her sleep pattern periodically, by waking up earlier, in order to accommodate the weekly morning oT session.

\section{Participant's Description of Their Children}

The participants' children with developmental delays were ages $101 / 2$ months (the Birches), 14 months (the Connors), and 24 months (the Adamses). The length of time that the three families had received occupational therapy home visits was three months, five months, and one year, respectively.

The children were typically described by their parents 
as being "slow" or "behind" in at least two areas of development. They all noted typical, positive traits in their child as well, or emphasized the need to treat their child "as a normal kid." One of the study criterion was that the participant's child would only be receiving occupational therapy at the time of the interview, thereby probably screening out children with more significant motor deficits, health complications, or low incidence conditions such as visual and hearing impairments. This appeared to be the case with all the children represented in this study. The Birches were the only parents who anticipated receiving physical therapy services for their son in the near future, indicating that their son may be more physically disabled than the children in the other families.

Recognition of Problem and Securing Assistance

Each participant came to realize their child's special needs in slightly different ways. However, all participants described a type of conflict between their personal intuitions and the opinions of doctors and others, and the need to integrate this information into their means of understanding and initial acceptance, prior to contacting an agency for occupational therapy services. The Adamses knew, somewhat, about the possibility of 
developmental delays, having adopted a hoy who was born two and a half months prematurely. Abe read books on prematurity, relied on friends' experiences, and tried not to worry, until it was obvious to him that he and his wife needed help. His wife went through a similar process, though emphasizing more the pediatrician's role in setting developmental landmarks. In all, it was six months before they contacted an agency.

The Connors had the experience of having four children previously, one of whom had similar delays as their child who is currently receiving OT home visits. They were thus able to recognize signs of atypical development in their fifth child within a couple months of his birth. Elsa took the initiative to call the developmental agency before the pediatrician suggested it. Frank also emphasized the need for parents to be aware of and accountable for problems in their children, instead of relying solely on doctors. The Connors are still going through the process testing to obtain a diagnosis, or to obtain answers about their son's devel opment.

The Birches were newest to the early intervention system, and seemed to be the most "caught off guard" by their experience. They noticed oddities in their son's movements, and a lack of typical play activity at about five months of age. Cindy expressed her concerns repeatedly to doctors and felt somewhat satisfied when a 
doctor referred her to an agency for a developmental evaluation, where an occupational therapist validated her concerns. The Birches are also going through a stressful period of extensive evaluations and tests, searching for answers, and as yet know only that their son's brain is lacking a corpus collosum, which connects the right and left hemispheres.

\section{Parent's Perception of the Occupational Therapy Home Program}

The Adamses receive OT for an hour, every other week, while the other two families have a therapist visit for an hour every week. All three mothers attend the OT home visit on a regular basis. Each of the fathers had attended at least one home visit, though it is not part of their typical routine.

All parents perceived the OTR to be leading the home visits, and that her job entailed hands-on therapy with the child, as well as educating the parents. Three parents described the OTR doing exercises with the child, with an emphasis on physical development.. Dale was the only parent who included play in his description of the therapist's activities. Brenda mentioned that the therapist brought toys to the home, however, she differentiated these from "learning tools" that the OTR brought. Overall, the home 
program was perceived favorably by everyone. When asked how a home program could best meet their needs, every parent expressed a desire to have more frequent home visits if it were possible.

\section{Parent's Role in Early Intervention}

All parents, with the exception of Abe, perceived themselves as taking an active role in early intervention. Abe did share the common belief, however, that the parent's role in early intervention included self-education. Each parent's learning style was slightly different. Abe primarily read books to learn more about premature births. Several parents increased their knowledge of developmental delay and intervention by asking their doctor or occupational therapist questions. All parents used observation as a tool for increasing their knowledge too, either by watching their occupational therapist during the home visit, or by observing their child's, and other children's, behavior.

The three mothers, and one father, described ways in which they performed therapy, or carried out activities with developmental goals, throughout the week. On the other hand, the three fathers, and one mother, emphasized that their role was not that of a therapist. 


\section{Role and Time Use}

\section{Abe Adams}

From his activity configuration, it was found that Abe sleeps an average of eight hours a night; eleven hours of his day are related to outside employment, two hours are spent on leisure, and an hour each is allotted for selfmaintenance and childcare on a typical weekday.

Abe described his life as quite set in its routine. His roles and time use were felt to be dictated largely by inflexible life circumstances, such as the economy and the family structure. In general, he felt satisfied with his life, and with the occupational therapy home program.

Abe does not attend the occupational therapy home visits, which are scheduled for one hour, every other week. However, to allow his wife to attend, he swaps roles with her on that particular day. She, then, is able to pick up their child from day care, attend the home visit, and then carry out the evening childcare and chores, which are typically part of his routine. Abe sees this schedule change as a nice break in his routine, allowing him the flexibility to stay at work longer, rather than rushing to pick up his son from day care. Other than this day, OT is not perceived as having any impact on his roles and time use.

Abe's husband and father roles were indicated as most 
enjoyable and he expressed the desire to spend more time with his son than he does now. Abe perceives his role as a worker to be his most demanding, as well as being a stressful reminder that he needs to provide for his family. However, work also provides him with a valuable sense of self-worth. Chores and childcare duties are divided equally between $A b e$ and his wife, and housework in particular is an undesirable task that he would like to spend less time doing.

Abe does not feel that he plays a significant role in his son's therapy, considering that to be his wife's domain. He generally associates the occupational therapy home visits with tests, evaluations and exercises. He does not perceive playing with his son as being related to occupational therapy, and feels that any more involvement with the home visit on his part would be stressful. His wife, however, believes that Abe is actually more involved than he realizes, as she sees him following through on play suggestions that she has passed along to him from the occupational therapist. His image of OT is positive, however; he sees it as being casual and enjoyable for his wife, as relieving his worries about his son's development, and a chief factor in his son's developmental progress. 


\section{Brenda Adams}

As indicated on her activity configuration, Brenda sleeps six and a half hours per night, devotes eleven or more hours toward outside employment, two to two and a half hours toward leisure, two hours for childcare, and one and a half to two hours for self-maintenance on a typical weekday.

Brenda generally enjoys her roles and use of time, recognizing that there are pros and cons to her life structure, but emphasizing that they are decisions that she has made herself. While she sees her work schedule as somewhat inflexible and time consuming, it is likewise very worthwhile and enjoyable. Brenda has also chosen to remain very involved with friends and close relatives, and does volunteer work for her alma mater sorority. She has not needed to adapt her schedule in any significant way to accommodate her son's special needs. Ideally, though, she would like to spend more leisure time on herself and with her child.

Overall, Brenda perceives occupational therapy as impacting the quality of time that she spends with her son, rather than the quantity of time. As a result of what she has learned during the home visits, she takes a more active role in her child's learning, which involves such activities as buying toys, goal-directed play, and routine childcare. 


\section{Cindy Birch}

As indicated on her activity configuration, Cindy sleeps seven hours a night, works outside the home nine hours, and spends four and a half hours on childcare. She explained that her daily two to four hours of selfmaintenance and hour of leisure overlap each other, as well as other occupational areas.

Except for the satisfaction and comradery that she receives through her employment, Cindy described a lifestyle that revolves around her son, resulting in frequent feelings of exhaustion and "burn out." She is very devoted to "working" with her son, notably from the onset of the occupational therapy home visits. However motivated she is to carry out the activities and exercises that she believes she is supposed to do, Cindy does not feel that she has adequate time for leisure with friends or herself, sleep, chores, or hobbies.

\section{Dale Birch}

As recorded on his activity configuration, Dale averages eight hours of sleep a night, spends about ten hours a day on outside employment, three hours toward childcare, two hours of leisure, and an hour of selfmaintenance.

Work often takes precedence in Dale's life, though he 
would ideally like to work less hours and spend more time with son, as well as have more time for leisure and home maintenance. Dale senses a slight imbalance in his roles and use of time, but notes that after the birth of any child, it is typical to have less time for things like hobbies, friends, and sports.

Dale believes that occupational therapy has impacted his time use qualitatively, rather than quantitatively, as he plays with his son in different ways now, trying to incorporate suggestions that the therapist has relayed. He very adamantly claims that he does not take on a therapist role with his child, "like his wife does," but rather, plays with his son. He also sees himself as a learner, observer, and family provider. Though he proclaims that his son will grow at his own pace regardless of the amount of therapy that he receives, Dale would like for his son to receive more home visits, if his wife had the time to attend.

\section{Elsa Connor}

Elsa sleeps an average of eight hours a night, works within the home with approximately six to six and a half hours of chores and self-maintenance, three and a half hours of childcare, and six hours of leisure.

Elsa feels an overall balance and satisfaction with her roles and daily schedule, though ideally she would 
spend less time on housework, while being able to build more friendships and have more leisure time and money for hobbies. She feels that she has a lot of support from her older children, who help out with chores and childcare.

Elsa notes that the occupational therapy influences the way that she observes and plays with her child. She emphasizes the relationship between parent and therapist to be as important as the skills that are taught.

\section{Frank Connor}

Frank typically sleeps six and a half hours a night, spends ten and a half hours toward outside employment, two and a half hours each on leisure and self-maintenance, and one and a half hours on childcare.

The roles that Frank and his wife have assumed may be described as disparate, yet compatible with their family and religious values, and the type of life that they have chosen. As sole financial provider for a spouse and five children, work is very important to Frank, even if not particularly enjoyable. He would rather have more time to spend with his children, or for doing more volunteer work. Ideally, Frank would like to have some time set aside for a hobby, primarily to allow himself the leisure of spending time alone to think. He would also like to develop more friendships with peers, though he perceives his current 
role obligations, and having two children with special needs, as impeding that desire.

Frank sees the current occupational therapy home visits as having a very minimal impact on his roles and time use, even less than when he experienced the home visits for his older child with developmental delays. However, he sees his role as a teacher enhanced, influenced by the current occupational therapy home visitor, as he now interacts and plays with his child in different ways.

He does, however, make a distinction between his "play" and the "work" that the occupational therapist does. Frank believes that more OT home visits would be beneficial.

\section{Themes Identified}

The themes identified through qualitative analysis of the data were the balancing act, sacrifices, establishing and relinquishing control, to each his own role, enabling families, belonging vs. isolation, and teamwork. Discussion of the themes is presented in Chapter 5.

\section{The Balancing Act}

[The therapist] comes about 10:15. [laugh] I don't get to sleep until 9:00 anymore, because I have to get up, and make sure, I like [to] have all the kids fed and clothed, and chores done, and 
me fed and clothed too, and so I try to get up earlier on that day. Elsa

[Wife] drops [child] off to daycare and I pick him up... I pick him up about 5:30 or 6:00, cook dinner for him, and cook dinner for us, and between that $6: 00$ and 8:00 time when [wife] and I eat, it's pretty much the same thing daily...Well...one day every other week is, is uh, I just stay at work late, I usually get home maybe 7:00 -or later- and we [husband and wife] kinda swap roles. Abe

With busy lives, and little time to spare, all of the participants were pragmatic in finding ways to balance their roles and use of time. Parents rearranged their schedules, or traded roles with their spouse, in order to accommodate the home visitor. For Elsa, Cindy, and Brenda, who were actually attending the home visit, it meant rushing through other daily tasks at work or at home. The fathers did this shuffling less often, but as needed, to support their wives, or to attend medical appointments or OT home visits on occasion.

In addition to making adjustments for the actual home visit, parents found ways to balance child development activities with their routine daily activities throughout 
the week. For instance, Brenda would name colors while getting her son dressed. Elsa found that she put more household responsibility on her other children in order to spend more time with her son with special needs.

I don't have a lot of time, um, to...the time that I do have to spend with the family, is very minimum. And is, so the time that I do spend, I like to spend as much as I can-but I can't spend it on just one child. I've got to disperse it as best as I can, so not each child-each child gets a little bit of interaction with their father so they know they have one. Frank

The balancing act was not a phenomenon limited to early intervention. In the above excerpt, Frank, like other parents, explained that he had to balance his time between his five children, as well as balance his role as a father with the role of being a one-to-one teacher to his son with developmental delays. The balancing act was not perceived by any parents to be a particular hassle; parents simply accepted these type of changes as a healthy part of adapting to life. 


\section{Sacrifices}

Yeah, a lot of work sometimes for now. I get so tired, you know, burned out, because before I like[d] to relax, watch some TV and some program... now I just stop everything. Most of the time I spend time with [child]. Cindy

I'm not always home when [the therapist] comes, so I mean, it's difficult for me because I'm always in the working mode, so I never.. I have been home when [the therapist] has been here, and [have] seen how she has worked on a couple occasions, but I haven't had the opportunity to be here all the time. I would like to be here. Frank

Whether perceived as being by personal choice, or outside circumstances, all of the participants expressed ways in which sacrifices were made in at least one area of their life to allow for more time in another. participants were very individual in the role choices that they had made, and in the areas in which they wished they had more time. As a group, they expressed how they did not have enough time for leisure/play/hobbies, selfmaintenance, work, friendships, sleep, more personal involvement with OT and therapy time with the child, as well as more frequent home visits. 
An individual's decision to make sacrifices was based on a myriad of reasons. Lack of time for preferred activities was blamed on having to spend too much time with paid and volunteer work, chores, childcare, or therapy activities. Other influences on role and time sacrifices included inflexible schedules, tough economy, religion, distracting thoughts, other family members, and personal desires. Some parents seemed to struggle with the dilemma of making a sacrifice more than others, and appeared guilty that they had made the choices that they had.

\section{Establishing and Relinguishing Control}

Well, there was one time when [the therapist] came to do an evaluation..., and [wife] had to do, had something important at work, but I insisted that she, uh, come here and do this because she'd been doing it for the past year. I thought I wouldn't be as effective, or understand a lot of the discussion if I came out of the vacuum and all of a sudden were discussing his progress over the past year... Abe

The participants expressed a range of feelings, from inadequacy to competence, and from powerlessness to feelings of control over decisions and outcomes of events. 
The issue of control was also very apparent in each parent's attitude toward early intervention, and his or her personal involvement in the home program. Cindy explained, "So, and then I start doing that [therapy] every day, and then he improve[d]...." Cindy felt that it was in her control, and thus her responsibility, to spend all the time that she could on increasing her son's development through techniques that she had learned from the therapist.

Cindy's husband, Dale, on the other hand, took the position that increasing his involvement in his child's development would not make much difference. "There's only so much therapy that you can do...he's going to develop pretty much on his own I think." Therefore, he perceived his own interaction with his child to be typical father-son play, and not therapy.

Finally, parents also fluctuated on their position of what was within or outside of their power in other areas of their lives. There were some role and time use patterns that parents did not feel capable of changing. For instance, roles that involved tasks such as work and household chores were often described as obligatory, routine, necessary, inflexible, or tolerable. Meanwhile, individuals perceived other life roles, and the manner in which time was structured within those roles, as a matter of choice. 


\section{Enabling families}

I just, I feel like part of my role as a parent is to help [child] out and to work with him. And the best way I can do that is by watching her and what she does, and work that into what we do with him. Elsa

The occupational therapist created an opportunity for Elsa to learn, but did not necessarily give her explicit instructions. All participants gave descriptions of the observation skills that they held before therapy began, and the occupational therapists seemed to build upon this skill. Parents used observation as a means to analyze their child's behavior, to compare against other measures, and to check and monitor their child's development. They used observation to gather information for themselves and for other caregivers and professionals.

Many parents felt that they had become more active in their child's learning with the help of the occupational therapist. In addition to acquiring observation skilis, parents learned how to enhance their parent-child play time by incorporating techniques that the OTR showed them. Most parents perceived that their primary roles and time use had not changed dramatically, but the quality, or how they performed their roles, was enhanced. 
To Each His Own Role

Because we're not, obviously we're not therapists, knowing that would be the best way to teach him. To learn how to crawl, or what have you. We need that kind of assistance. I mean I had, I would have no idea if $I$ came in and saw a child like this -where would you start? You got me. So that's, I think, the main role for the therapist to come in. Frank

Frank also believed that he had an advantage over other families, because he and his wife had the experience of having another child with similar delays. They had gone through the process before. Still, they felt that they needed the special services of an occupational therapist (OTR).

All participants gave examples of roles and tasks that were within the parents' domain and those that were within the therapist's domain. Though each parent's perception of how the role of an OTR differed from that of a parent, no one seemed to be experiencing role confusion, regarding his or her personal position.

As a group, parents acknowledged that they had a special role in their child's development and OT home program. These included, being there for their child, to encourage, help, play, bond with, discipline, comfort 
and calm the child. Parents also expressed their responsibility for their child's progress and future, obtaining medical care and attending appointments. Every parent believed that one of their roles was to treat their child normally, even those who appeared to spend an inordinate amount of time performing therapy-related tasks with their child. In general, parents said they did what they could, based on what they were capable of doing.

Parents also noted unique qualities of an occupational therapist. For all but one parent, the OTR was perceived as a teacher and mentor. The OTR was described as being one who teaches, shows, explains, models, answers questions, gives practical and tangible advice, and brings learning tools to the home. At times, the OTR was perceived as an authority figure, as someone who gives her "students" assignments. As a group, the parents described the therapist as one who works one on one with the child, comes up with new ideas, anticipates parents' needs, searches the literature for relevant topics to share with parents, has a professional routine, establishes goals and objectives, sets parameters for how goals will be carried out, and establishes a starting point so parents know where to begin helping their child. Her specific activities also include exercises, and using little "tricks" to get a child to perform gross motor skills. 
Only two participants mentioned "play" or "toys" when describing the therapist's role. The OTR's role was generally perceived as more serious and different from the play in which parents engage with their children. In all cases, the therapist played a lead role during the home visit, while the parent generally waited for directions.

\section{Belonging vs. Isolation}

So, I guess, you know, a lot of people have the luxury of just watching their child grow and say "Isn't that cute?' 'Isn't that wonderful?' and not really have to work on certain areas.... I think it's been wonderful, because we've taken probably more of an active role in his learning and things like, that he needs to work on, maybe more than the average parent might have, because they could take it for granted. Brenda

All the parents recognized how having a child with special needs required them to take on unique roles. The Connors felt that having a child with special needs, two children actually, increased their childcare obligations and isolated them from socializing with other adults. However, they did not perceive the OT home program itself to be affecting their lives significantly. Cindy, on the other hand, felt that her roles and time use were different 
from her peers who had children, particularly since becoming involved in the OT home program. In the passage above, Brenda described a positive aspect to being set apart from other families, though three parents described apprehension at the idea that their child may not be "normal."

While the participants contrasted their roles and time use with other families, half of parents also stated that their roles and time use was typical of most families. "We are just like any other family, only different," seemed to be what these parents were saying. They expressed a general need to be like everyone else. Being a part of the work force or other organized group seemed to be especially valuable to participants' self-esteem and belonging, despite the many comments that they wished they worked less hours. For cindy, who seemed to be overwhelmed by the perceived need to spend her free time actively involved with her child, work was a haven. Work served as her place of belonging and social support, while staying at home with

her child with special needs was the perceived source of isolation.

\section{Teamwork}

Well, I'm kind of on the sidelines, I'm not here... But the time I was here, you know, I helped 
hold him and stuff like that. So, you know, you're involved when she's here. You know, you feel like you're part of the team. Dale

I can't just totally devote every second to the child and then give nothing to my husband. I need a support. So it's something that you really have to work together as a team. Elsa

It's difficult because I'm not always here, but I talk to [therapist], and she knows what I want, what I'm looking for. And I told [wife]. So the combination of the two...they have, they have done what $I$ feel is correct. Frank.

Some parents felt helpful and important by directly participating in any way they could during the home visit and throughout the week. Two of the fathers, who did not usually attend the home visit, nor felt like they participated in "therapy," still perceived themselves to be part of the early intervention team. Good teamwork among all family members seemed to be fostered largely by the occupational therapist. Teamwork was also obtained from relying on family members, including other children, spouses, and extended family members. Although Abe perceived himself to be very removed from the OT service, 
both he and his wife tended to respond to questions using "we," portraying a united team effort on the part of husband and wife. In the last narrative example, Frank described his experience with the first child that he had with developmental delays. During that first experience, he did not feel that his needs were being expressed, partly due to the therapist's approach, and partly due to not sharing the same views as his wife. It took the act of the parents collaborating as a couple, joined with an understanding therapist, before the three could act as a team.

\section{Answers to Research Questions}

The answers to the research questions are presented as a synthesis of role and time use findings and the emergent themes.

\section{Question 1}

How does the parent of a child with developmental delays, who is participating in an occupational therapy early intervention home program, perceive his or her present time use and roles? Parents perceived their time use and roles as being part of a larger system, as being hierarchial in nature, as having limited flexibility, and as being unique. 
Roles and Time Use as Part of a Larger System

Evident in the theme "the balancing act" was parents" implicit perception that their roles and use of time occur within larger family and societal systems. As these parents made a shift from one role to another, or altered the way in which a block of time was used, repercussions were felt in several areas. The parents generally did not perceive these shifts and balances as a hardship, or as unique to a parent of a child with special needs. Rather, like most people, they found creative ways to compromise, to keep themselves and everyone else relativel $y$ happy.

Roles and Time Use as Being Hierarchial in Nature

As described in the theme "sacrifices," parents perceived some roles to take precedence over others. Not all roles and time schedules were considered to be flexible, or capable of being shifted, regardless of other significant changes that were occurring in the family system, such as the introduction of a home based early intervention program. As a result, parents sacrificed some activities, or entire performance areas, rather than make changes in an area that was perceived as commanding a high priority. Each parent could not perform all his or her desired activities to satisfaction, thus reacted by defending his or her choice of actions, or by expressing 
feelings of being burdened.

Roles and Time Use as Having Limited Flexibility

Related to the interdependence of roles and the hierarchy of role priorities, described in the preceding paragraphs, parents perceived a limit to the flexibility that they had in making role and time use choices. As elaborated in the theme, "establishing vs. relinquishing control," there was not a single unifying perception that an individual's roles and time use were either completely beyond or within one's control. Some parents held a more optimistic view that they ultimately had control over the roles that they assumed, and that they were free to choose how their time would be spent. Those who expressed having a greater sense of control did not necessarily seem to be more or less satisfied with their roles, or did not appear to be more or less defensive in describing their roles and time use.

Roles and Time Use as Unique

In the theme, "to each his own role," parents described the disparity that they saw between their unique roles as a parent, and the roles of an occupational therapist. The theme, "belonging vs. isolation," revealed that there were also perceived role and time use distinctions between mothers and fathers, and between the participants and parents of typically developing children. Cindy, Elsa, and Frank, for instance, described how having 
a child with special needs decreased the amount of time that they could spend on activities outside the home, such as shopping and leisure and social activities.

\section{Question 2}

How does the parent of a child with developmental delays perceive the impact of an occupational therapy early intervention home program on his or her life roles? Parents perceived the occupational therapy home program as either consuming their other life roles, as having a positive, or as having no impact at all. Home Program is Consuming of Life Roles

Some parents perceived the OT home program as responsible for instigating new roles, or broadening existing roles, to the point that other life roles were compromised. For instance, following exposure to a home program, one parent neglected peer friendships and tasks centered around her role as a wife, in order to be more involved in a therapeutic role with her child. She felt burdened by her perceived responsibility of providing therapy for her child. This belief appears to stem from her personal values, however, and not from actual responsibilities placed on her by the occupational therapist. 


\section{Impact of Home Program on Roles as Positive}

Most parents saw their therapists as enhancing the skills and roles that they already possessed, and introducing new skills, as explained in the theme "enabling families." One parent also described how the oTR was able to incorporate the role of siblings into therapy in a positive way. As described in the theme, "teamwork," therapists played a vital role in helping some parents to feel like part of a parent/therapist team. This was not apparent in parents' descriptions of other parent/ professional relationships. No Perceivable Impact of Home Program on Roles

Many parents expressed that the home program had absolutely no impact on their roles. Rather, they found that their life roles impacted the manner in which they became involved in OT. Participation in OT was sometimes sacrificed for roles and activities that were already part of the parent's established routine.

\section{Question 3}

How does the parent of a child with developmental delays perceive the impact of the occupational therapy early intervention home program on his or her time use? Parents viewed the impact of the home program on their time use as either positive, negative, neutrally acceptable, or as having no impact. 
Home Program Has Positive Impact on Time Use

In some instances, the home visit actually gave the parents "permission" to spend more time doing the very things that they wanted to do. Brenda, who typically spends 11 hours a day working and commuting, was happy to be able to spend a little more time with her child on the days that the therapist came to visit. On the rare occasions that Frank was home during the therapist's visit, he enjoyed keeping the older children occupied while the OTR spent time with the infant. Had Frank's assistance with the other children not been required, he would not have spent the time interacting with them, even though he would have liked to do so more often.

Home Program Has Negative Impact on Time Use

One parent appeared to suffer a loss of personal time, for the sake of a home visit program. Cindy perceived OT activities as impacting her use of time, as she spent three hours a day performing therapy activities with her child. She also missed the time that she used to spend in the areas of rest, leisure, and self-maintenance. Home Program Has an Acceptable Impact on Time Use

Four of the parents provided concrete examples, in the theme "the balancing act," of ways in which they adapt their time use in order to schedule the occupational therapy home visits. All of the fathers had been able to 
attend at least one hour long home visit. The schedule changes made to do so were described as acceptable or tolerable. The mothers who met with the oTRs regularly seemed somewhat rushed by the balancing act required to attend the meeting, but not inconvenienced.

The three mothers who were interviewed also set aside specific amounts of time for the therapeutic activities with their child. Scheduling of time outside of the home visit was perceived to be largely initiated by the parents. Brenda and Cindy also perceived that the therapist had some expectations that the parents would spend some time during the week performing suggested activities or exercises, though no one believed that the therapist actually dictated the amount of time that should be spent on therapeutic activities, or when the time should be spent.

Home Program Having No Impact on Time Use

Four parents stated that the home visit had no impact on their daily time schedule. Although the preceding paragraphs show evidence that $O T$ was not devoid of making an impact, it was clear that the majority of the parents did not see their schedules as noticeably changing, due to the introduction of a home program. The fathers, in particular, did not see themselves structuring their time any differently. Although they sometimes participated in therapeutic play alongside their wives, fathers believed 
that it was time that they would have spent playing with their child anyway.

Each of the mothers, although they also set aside certain "therapy" time, indicated ways in which OT principles or techniques were incorporated into the daily routine without disrupting the normal schedule. They commented how their daily schedule often dictated how occupational therapy would be incorporated, not the other way around. However, when parents disclosed that OT was not impacting their time use, they often used apologetic tones, and quickly gave a defense explaining why it was not. 


\section{CHAPTER 5}

\section{DISCUSSION WITH IMPLICATIONS FOR THE PROFESSION}

In this chapter, the researcher presents a discussion of the themes and the answers to the research questions that emerged from the analysis of the data, reported in chapter 4. Literature that supports or refutes the data is presented. The results are related to general systems theory, the occupational behavior frame of reference, and the family focus movement in early intervention. Implications for occupational therapists in early intervention and suggestions for future research are also provided.

\section{Themes and the Literature}

The themes, "the balancing act" and "sacrifices," were fairly consistent with the literature describing the time commitments and limited role choice of parents of children with disabilities (Friedrich \& Friedrich, 1981; Johnson \& Dietz, 1985; Lucca \& Settles, 1981). In the themes, "to each his own role," and "belonging vs. isolation," parents further revealed perceptions of excessive role and time demands. However, negative perceptions were generally buffered by feelings of empowerment, sense of family normalcy or good relationships, as revealea in the themes, 


\begin{abstract}
"establishing and relinquishing control," "enabling families" and "teamwork." Teamwork, which characterized the spirit felt between family members or between parent and therapist, was a prominent factor in all positive early intervention home program experiences. A similar theme, labeled "the third parent," was revealed in Hinojosa's study (1990), in which some of his study participants perceived their therapist as a close friend of the family.
\end{abstract}

\title{
Discussion of Research Questions
}

\section{Perception of Current Roles and Time Use}

The six subjects assumed roles and schedules that appeared to be typical of American families. Specific roles and time use were unique to each individual, and each parent shared different perceptions regarding roles and time use. Thus, there were not particular traits that defined parents of children with developmental delays.

Only one parent among the six reported feeling emotional and physical fatigue related to occupational therapy. Perhaps her child's young age, and apparent need for a higher level of physical care than the other children, exacerbated the requirements of her role. studies of parents of children with physical disabilities, tend to find that the functional level of the child is a factor in the parent's level of stress, roles, and time use 
(Lucca \& Settles, 1981; Smith, 1986).

As a group, the fathers in this study appeared to have unique perceptions from the mothers. Fathers of children with developmental delays have been perceived as susceptible to feelings of inadequacy in fulfilling traditional parental roles (Barber, Turnbull, Behr \& Kerns, 1989). The fathers in this study were generally happy with their roles and time use. Their greatest sources of discontent were the demands of work and the shortage of time available to spend with their child. Two fathers also perceived themselves as less adequate than their wives in carrying out childcare and therapeutic tasks, even in the context of play and daily activities. Furthermore, they were not interested in making any role or time schedule changes to become more involved in early intervention. This is consistent with Anderson and Hinojosa's reproach (1984) that parents may not be ready to take on new roles and therapist-like responsibilities. The third, more experienced, father in this study reported taking a passive role in the past, but currently portrayed greater role confidence and proactivity. This may be characteristic of experienced parents in general.

\section{Perception of Impact of Occupational Therapy}

Just as parents perceived their present roles and time use in unique ways, their perceptions of the impact of an 
early intervention home program on roles and time use varied considerably. Within the six interviews, all possible responses to the impact of the home program on roles and time use were expressed. Occupational therapy was perceived at various times as being responsible for creating positive changes, negative changes, neutral changes, as well as no changes, in parents' roles and time use.

Whether parents claimed to follow through on therapy activities during the week or not, parents perceived that the OTR had at least minimal expectations of their involvement in early intervention. They seemed almost reluctant to admit when OT had made no change in their roles and time use. The pervasive view of the OTR as an authority figure was also revealed in the themes "establishing and relinquishing control" and "to each his own role." Therapists were perceived as having unique roles that could not be fulfilled by a parent, and thus, control of the early intervention process was sometimes felt to be in the hands of the therapist.

However, parents acknowledged that their personal involvement in early intervention was largely determined by their personal motivation and life circumstances, rather than by therapeutic tasks prescribed by the OTR. The OTR did not have specific goals directed toward parents, as was 
predicted to be the future direction of early intervention (Anderson \& Hinojosa, 1984), and did not suggest how the parents might organize their time. If the OTR had an impact on life roles or daily schedules, outside of parenting and early intervention, it was perceived to be inadvertent, and not part of the therapist's agenda.

The occupational therapy home program was praised by every parent. This being the case, why did one mother feel burdened and obligated as a parent to keep up a therapy routine with her child, at the sacrifice of leisure, social, and self-maintenance activities? One possibility is found in the theme, "establishing and relinquishing control." The parents who felt that OT had an impact on their roles and time use also felt greater confidence and control by being able to aid their child's development. Those who were not as inclined to perceive a change in themselves, at least felt reassured that the therapist was there to help their child's progress. At the extreme, then, a parent may feel so much need for control, that he or she cannot release any role responsibilities to another person. As a parent who is newly, coping with her child's disability, this may be a coping mechanism that cannot be easily dismissed.

Relevance to systems Theory and Occupational Behavior 
consistent with the principles of general systems theory. Roles and time use were perceived as part of larger systems; they were not determined in isolation from other family members, social circumstances, and obligations.

The fact that there were changes in parents' time use and roles with the introduction of a home program exemplifies the principle that changes in one subsystem results in repercussions in others. This coincides with the admonition that the family must be considered a unit and changes in one individual in the family must be viewed as potentially affecting all members (Roberts, et al., 1991). Parents who did not perceive such changes were exhibiting the hierarchial nature of roles in the theory of systems. The obligations of higher order roles did not permit parents much flexibility in their roles.

A primary objective of occupational therapy, from an occupational behavior frame of reference, is to aid individuals in meeting the requirements of their roles. Parents did not appear to demonstrate true role dysfunction, or an inability to meet their role requirements, though everyone struggled at some time in order to adapt to his or her role demands. All parents felt that the role demands in at least one area of their life were excessive to the point of needing to sacrifice energy spent performing other tasks. 
Parents did not report feelings of role ambiguity, but it was clear that each parent had a different perception of the distinction between the therapist's role and his or her personal role in early intervention. Perceptions differed between spouses as well as between therapist and parent. These issues of role dissatisfaction and delineation of roles warrants further investigation by occupational therapists.

\section{Relevance to the Family-Centered Approach}

The results of this study support many of the principles and ideals of a family-centered approach in early intervention. Each participant positively described examples of the occupational therapist promoting collaboration, enablement, and empowerment. All of the parents all had positive views of the occupational therapist and the home visits, and each one expressed a desire to have more frequent home visits.

Yet, the data also indicated that parents still held perceptions of role distinctions between the OTR and the parent that are reminiscent of a child-centered approach. Parents seemed to occasionally doubt their control and competency, particularly early in the process of obtaining services for their child with developmental delays. They voiced discrepancies in all occupational performance areas 
between their ideal roles and time use, and what they were currently doing. Furthermore, parents discussed with the researcher several perceptions and preferences that had previously been uncommunicated to their therapist, indicating a continuing need for greater communication between parents and professionals.

Guidelines for current early intervention practice indicate that a caregiver's need is only a need if he or she identifies it as such (McGonigel \& Johnson, 1991). It is not a family-centered practice, for instance, to make inquiries regarding parents' current roles and time use unless the family identifies it as a concern relevant to their child's development. The parents in this study did express such needs as desiring fewer role obligations, and increased free time, whether it would be to spend with their child, or to take a break from the child. Some felt unable to meet the demands of their multiple roles to their personal satisfaction. However, it did not seem likely that these parents would use the IFSP process to request assistance in balancing their roles and time use, particularly when it is not commonly identified among parents, or even other early intervention professionals, as being in the domain of occupational therapy. Nevertheless, it would be reasonable for occupational therapists to act as consultants in this area, while staying within the spirit of family-focused collaboration. 
Implications for Occupational Therapists

Integrating the principles of general systems theory and occupational behavior into the family-centered approach, the OTR should seek to learn of the parent's personal role priorities and time obligations, as well as the parent's perceived role conflicts, excessive role demands, and desired role in early intervention.

The first step seems simply to utilize good communication techniques, starting from the first parentprofessional meeting. By asking parents to choose how they would like to be involved in the early intervention process, and offering different options for both mothers and fathers, occupational therapists can help restore a sense of control to the parents. Care must be taken when interpreting parents' true meanings during these discussions. For instance, many parents in this study discussed their role of "working" with their child. However, further investigation revealed that their definitions of "work" varied. Listening to and validating parents' concerns and opinions also seemed to be greatly appreciated by the parents in thi's study.

The use of an activity configuration in this study appeared to be one successful method of helping parents to see how their time is organized. For instance, one parent noted that the activity configuration was very eye- 
opening, as she had not previously realized how much time she spent at work. A visual tool, along with pertinent questions, could help parents to decide for themselves the areas they would like to prioritize, and those they would like to change. Such a tool could be introduced on an individual basis after good communication had been established with the family.

Johnson and Dietz (1985) suggested that, for mothers of disabled children who are dissatisfied with the discrepancies between their time use and that of mothers of nondisabled children, efforts should be directed toward finding and evaluating ways of freeing the mothers' time. The option of in-home respite care for children with disabilities, for as little as an hour a week, enabled some parents (Joyce, Singer, \& Isralowitz, 1983) to spend more time with other family members, pursue leisure activities, and to feel less guilty about leaving their child.

However, respite care may not be a desirable option for the working participants in this study who said that they wanted to spend more, not less, time with their child. For these parents, especially the mothers who tended to express a greater obligation in carrying over therapy outside of the home visit, other options need to be explored. It is suggested that therapists emphasize the importance of play and typical childcare routines in child development, as these were also roles that parents accepted 
as being enjoyable and uniquely theirs. This approach would also serve to empower parents by decreasing the persistent assumption that the occupational therapist is the primary agent of change in the child's development, and that "more therapy is better."

Although none of the parents in this study attend a support group, some type of community activity for parents and their children might be beneficial, as teamwork, good relationships, and a sense of belonging among friends was perceived as being valuable contributors to role satisfaction. Informal gatherings, or simply a directory of other families to call upon, may be utilized more than groups led by professionals.

\section{Suggestions for Future Research}

With the intention of full implementation of Part $H$ of the Individuals with Disabilities Education Act (1990), there will be the need for research on therapists' interpretation and compliance with a family-centered approach, and families perceptions of the impact of occupational therapy home programis on roles, time use, and other measures of family life. With a shortage of occupational therapists to meet the needs for early intervention home visits, other professionals will be involved in home visits as well. Research will be 
needed to explore the efficacy of consultation and transdisciplinary approaches, as training other professionals in the importance of parents' roles and time use is as important as direct service with families. While the participants in this study had similar sociocultural backgrounds, families typically served by early intervention agencies may represent different ethnic groups, may be non-English speaking, or include extended family members. Further studies are recommended with subject samples that reflect this diversity. One particularly unique family structure is that of the foster family. A large proportion of children receiving early intervention services live with foster families. These parents may have greater role and time demands, and different perspectives on childcare, that need to be taken into account in the study of the impact of early intervention on the family. 
REFERENCES

Ackoff, R. L. (1974). Redesigning the future. New York: John Wiley \& Sons.

Allen, D. A., \& Hudd, S. S. (1987). Are we professionalizing parents? Weighing the benefits and pitfalls. American Journal of Mental Retardation, 25, 133-137.

Anderson, J., \& Hinojosa, J. (1984). Parents and therapists in a professional partnership. American Journal of Occupational Therapy, 38, 452-46I.

Arango, P. (1989). Family-centered care: Making it a reality. In B. E. Hanft (Ed.) Family centered care: An early intervention resource manual (pp. 3-3-3-9). Rockville, MD: AOTA.

Barber, P. A., Turnbull, A. P., Behr, S. K., \& Kerns, G. M. (1989). A family ststems perspective on early childhood special education. In S. L. Odom and M. B. Karnes (Eds.), Early intervention for infants \& children with handicaps: An empirical base (pp. 179-1970). Baltimore: Paul H. Brookes Publishing.

Bazyk, S. (1989). Changes in attitudes and beliefs regarding parent participation and home programs: An update. American Journal of Occupational Therapy, 43, 723-728.

Bricker, D. \& Casuso, V. (1979). Family Involvement: A critical component of early intervention. Exceptional Children, 46, 108-117.

Christiansen, C. (1991). Occupational therapy intervention for life performance. In C. Christiansen \& C. Baum (Eds.), Occupational therapy: Overcoming human performance deficits (pp. 3-43). Thorofare, NJ: SLACK.

Christiansen, C., \& Baum, C. (Eds'.). (1991). Occupational therapy: Overcoming human performance deficits. Thorofare, NJ: SLACK.

Crnic, K. A., Greenberg, M. T., Ragozin, A. S., Robinson, N. M. \& Basham, R. B. (1983). Effects of stress and social support on mothers and premature and full-term infants. Child Development, 54, 209-217.

Crnic, K. A., Greenberg, M. T., Robinson, N. M., \& Ragozin, 
A. S. (1984). Maternal stress and social support: Effects on the mother-infant relationship from birth to eighteen months. American Journal of Orthopsychiatry, 54, 224-237.

Cynkin, s. (1979). Occupational therapy: Toward health through activities. Boston: Little, Brown.

Dunn, W., Campbell, P. H., Oetter, P. L., Hall, S., \& Berger, E. (1988). Occupational therapy services in early intervention and preschool services. Reference manual of the official documents of the American Occupational Therapy Association. Rockville, MD: AOTA.

Dunst, C. J., \& Trivette, C. M. (1987). Enabling and empowering families: Conceptual and intervention issues. School Psychology Review, 16, 443-456.

Dunst, C. J., Trivette, C., \& Deal, A. (1988). Enabling and empowering families: Principles and guidelines for practice. Cambridge, MA: Brooks \& Brooks.

Education for All Handicapped Children Act of 1975, (Public Law 99-142), 20 U.S.C. \$ 1401.

Education of the Handicapped Act Amendments of 1986 (Public Law 99-457), 20 U.S.C. ร 1400 (1987).

Friedrich, W. N., \& Friedrich, W. L. (1981). Psychosocial assets of parents of handicapped and nonhandicapped children. American Journal of Mental Deficiency, 85, $551-553$.

Glaser, B. G., \& Strauss, A. (1967). The discovery of grounded theory: Strategies for qualitative research. Chicago: Aldine.

Gorga, D. (1989). Occupational therapy treatment practices with infants in early intervention. American Journal of Occupational Therapy, 43, 731-736.

Haber, J. S. (1991). Early diagnosis and referral of children with developmental disabilities. American Family Physician, 43(1), 132-40.

Hanft, B. (1988). The changing environment of early intervention services: Implications for practice. American Journal of Occupational Therapy, 42, 26-33.

Hinojosa, J. (1990). How mothers of preschool children with cerebral palsy perceive occupational and physical 
therapists and their influence on family life. Occupational Therapy Journal of Research, 10(3), 144162 .

Hinojosa, J., \& Anderson, J. (1991). Mother's perceptions of home treatment programs for their preschool children with cerbral palsy. American Journal of Occupational Therapy, 45, 273-279.

Humphrey, R. (1989). Early intervention and the influence of the occupational therapist on the parent-child relationship. American Journal of Occupational Therapy, $43,738-742$.

Individuals with Disabilities Education Act of 1990 (Public Law 10I-476), 20 U.S.C. \$ 1400.

Individuals with Disabilities Education Act Amendments of 1991 (Public Law 102-119), 20 U.S.C. \$ 1400.

Johnson, C. B., \& Deitz, J. C. (1985). Activity patterns of mothers of handicapped and non-handicapped children. Physical \& Occupational Therapy in Pediatrics, 5(1), 1716.

Joyce, K., Singer, M. , \& Isralowityz, R. (1983). Impact of respite care on parents' perception of quality of life. Mental Retardation, 21, 153-156.

Kielhofner, G. (1977). Temporal adaptation: A conceptual framework for occupational therapy. American Journal of Occupational Therapy, 31, 235-242.

Kielhofner, G. (1992). Conceptual foundations of occupational therapy. Philadelphia: F.A. Davis.

Kielhofner, G., \& Burke, J. P. (1980). A model of human occupation, Part 1 . Conceptual framework and content. Aiüican Journal of Occupational Therapy, 34, 572-581.

Lawior, M. C., \& Henderson, A. (1989). A descriptive study of the clinical practice patterns of occupational therapists working with infants and young children. American Journal of Occupational Therapy, 43, 755-764.

Lucca, J. A., \& Settles, B. H. (1981). Effects of children's disabilities on parental time use. Physical Therapy, 6l(2), 196-201.

Mather, J. \& Weinstein. (1988). Teachers and therapists: Evolution of a partnership in early intervention. 
Topics in Early Childhood Education, I(4), I-9.

McGonigel, M.J. (1991). Philosophy and conceptual Eramework. In M. J. McGonigel, R. K. Kaufmann, \& B. H. Johnson (Eds.), Guidelines and recommended practices for the individualized family service plan (2nd ed.) (pp. 7-14). Bethesda, MD: Association for the Care of Children's Health.

McGonigel, M. J., \& Garland, C. (1988). The individualized family service plan and the early intervention team: Team and family issues and recommended practices. Infants and Young Children, I(1), 10-21.

McGonigel, M.J., \& Johnson, B. H. (1991). An overview. In M. J. McGonigel, R. K. Kaufmann, \& B. H. Johnson (Eds.), Guidelines and recommended practices for the individualized family service plan (2nd ed.) (pp. 1-5). Bethesda, MD: Association for the Care of Children's Health.

Moersch, M. (1989). Parent and family involvement. In P. Pratt \& A. Allen (Eds.), occupational therapy with children (pp. 132-146). St. Louis: C. V. Mosby.

Moxley-Heagert, L., \& Serbin, L. A. (1983). Developmental education for parents of delayed infants: Effects on parental motivation and children's development. Child Development, 54, 1324-1331.

Patton, M. Q. (1980). Qualitative evaluation methods. Beverly Hills: SAGE Publications.

Poyadue, F. S. (1988). Parents as teachers of health care professionals. Children's Health Care, 17(2), 82-84.

Reilly, M. (Ed.). (1974). Play as exploratory learning. Beverly Hills: Sage.

Roberts, R. N.; Wasik, B. H.; Casto, G., \& Ramey, C. T. (1991). Family support in the home- Programs, policy, and social change. American Psychologist, 46(2), 131 137 .

Rodger, S. (1986). Parents as therapists: A responsible alternative or abrogation of responsibility? Exceptional Child, 33(1), 17-27.

Ross, G. S. (1984) Home intervention for premature infants of low-income families. American Journal of 
Orthopsychiatry, 54(2), 263-270.

Sanik, M. M. , \& Mauldin, T. (1986). Single versus two parent families: A comparison of mother's time. Family Relations, 35, 53-56.

Schaaf, R. C., \& Mulrooney, L. L. (1989). Occupational therapy in early intervention: A family-centered approach. American Journal of Occupational Therapy, 43, $745-754$.

Schlaff, C. (1991, March 22). Communication between helping professionals and parents of handicapped children. Occupational Therapy Forum, 6-7, 12-13, 18.

Shannon, P. D. (1988). Occupational behavior frame of reference. In H. L. Hopkins, \& H. D. Smith (Eds.), Willard and Spackman's occupational therapy (pp. I42149). Philadelphia: J. B. Lippincott.

Shonkoff, J. P., \& Hauser-Cram, P. H. (1987). Early intervention for disabled infants and their families: A quantitative analysis. Pediatrics, 80, 650-658.

Shonkoff, J. P., Hauser-Cram, P., Krauss, M. W., \& Upshur, C. C. (1988). A community of commitment: Parents, programs and the early intervention collaborative study. Zero to Three, $8(5), 1-7$.

Short-Degraff, M. A. (1987). Commentary on 'Home environment and adjustment in families with handicapped children: A canonical correlation study.' Occupational Therapy Journal of Research, I(2), 83-92.

Smith, R. W. (1986). Physically disabled children and parental time use. Journal of Leisure Research, 18(4), 284-299.

Maylor, S. J., \& Bogdan, R. (1984). Introduction to qualitative research methods. New York: John Wiley \& Sons.

Turnbull, A. P., \& Turnbul1, H. R. (1982). Parent involvement in the education of handicapped children: A critique. Mental Retardation, 20(3), 115-122.

von Wendt, L., Ekenberg, L., Dagis, D., \& Janlert, U. (1984). A parent-centred approach to physiotherapy for their handicapped children. Developmental Medicine \& Child Neurology, 26, 445-448. 
Zisserman, L. (1981). The modern family and rehabilitation of the handicapped: A macrosociological view. American Journal of Occupational Therapy, 35, 1320. 
APPENDIX A

ACTIVITY CONFIGURATION 
College of Applled Sciences and Ars - Depirinert cl Oceupatlonal Therapy

One Washington Square - San Josd, Calitcimia g5192 ¿́cso

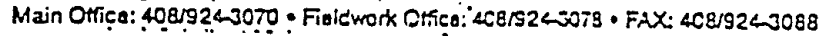

Each pie slice reyresents ore hou = of a weekday. Please shade in each slice to show agproximately how mang hours you spend daily in each category of life activity. (Use a different color or shading pattera for each category)

\section{CATEGORIES :}

Rest: sleep, naps

Work: paid job, voluntee = job, school

Play: leisure, recreation, non-work activity

SelE-Maintenance: s=oomins, tysiere, eating, chores

Childcare: dressing, bathing, thezapy/bealth related

other: add your owis categosi if needed

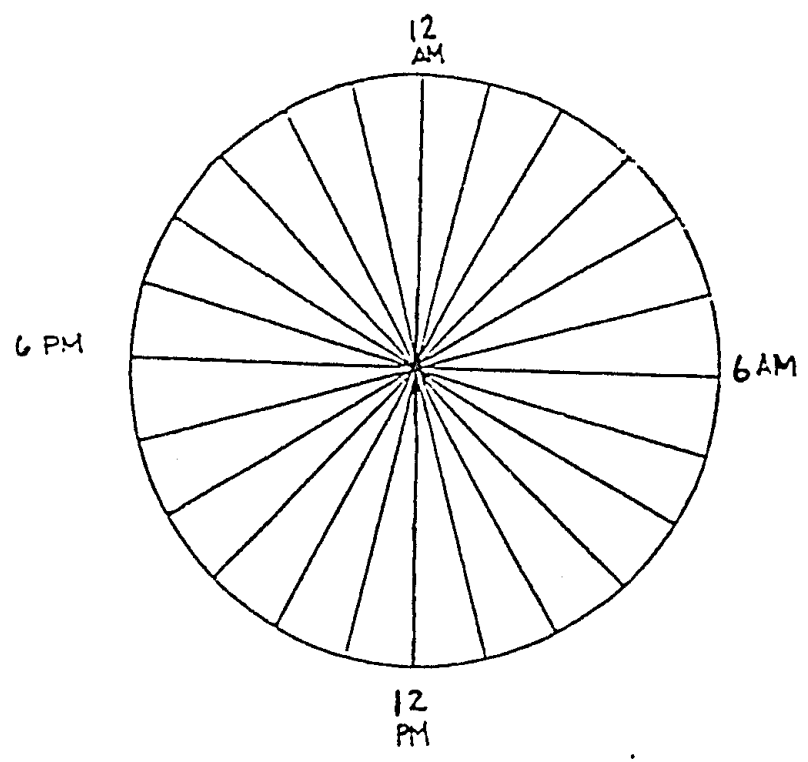

Please circle all of you majo: life roles.

husband/WiEe

mother/father

other Eanily remie=

other care siver

friend

worker voluateer

hobiyist/amateur

bome maintainer

religious participant

pa=ticipant in organizations other 
APPENDIX B

INTERVIEW GUIDELINE 


\section{INTERVIEW GUIDELINE}

\section{A. ABOUT THE DEVELOPMENTALLY DELAYED CHILD}

1. Tell me about [your child]. Probe for: Child's age, functioning level, reason for occupational therapy, age when delay suspected/ discovered, length of time in OT, other services received, ages of siblings, other caretakers.

B. ABOUT OCCUPATIONAL THERAPY SERVICES

1. What happens during the home visit? Probe for: Description of typical visit, length of session, parent's role and feelings during the process, involvement in decision making, nature of therapist's interaction (as parent educator, collaborator, etc.).

2. What type of influence does the home program have on your typical weekly schedule?

Probe for: Space made for OTR visits, specific therapeutic/play activities carried over (directed by parent or therapist), parent participation in groups, reading, preparation for next home visit.

C. CURRENT LIFE ROLES AND TIME USE

1. How do you define your role in the whole early intervention process?

Probe for: the caring, education, therapy... of the child.

2. What roles do you have outside of caring for your child? Probe for: (consult activity configuration for ideas), roles involving work, leisure, rest, self-care, etc.

3. How do you feel about [your roles] in general? Probe for: positive/negative feelings, parent's ideal, what would they change?

4. How do you feel about the way your time is spent in fulfilling these roles?

(Use activity configuration as a guide)

Probe for: pros/cons, what they would change, activities they wish they could spend more/less time doing

5. Who or what has influenced your roles and time use? Probe for: family members, therapist, upbringing, job schedule, etc. 
6. In what way, if any, does the occupational therapist or the OT home program influence your roles and time use? Probe for: the impact on: self-care/daily chores, time with children, leisure/rest, employment/volunteer work.

D. CHANGES IN LIFE ROLES AND TIME USE

Most people's daily activities and life roles go through changes with the birth of a child, and are continually changing as the child grows, especially if the child has special needs...

1. How would you compare your roles now (as mentioned above)

to what they were like before the onset of the OT home program?

2. How would you compare your time use now (as noted on the activity configuration) with your time use before the OT home program?

3. How do you think the OT program influenced these changes, if at all?

Probe for: Impact oT has made on roles, time use, more or less responsibilities, conflicts in roles, change in interaction with child/other people.

4. How do you feel about the changes, if any, which have taken place?

Probe for: Satisfaction level, expectations of OT

E. IN SUMMARY

1. How could a home program best meet your needs?

2. Is there anything you would like to add or clarify? 
APPENDIX C

INTRODUCTION LETTER TO SUBJECT 
Dear Parent:

My name is Justine Alcocer; I'm an occupational

therapist employed with the Agency for Infant Development in Eremont, California. I am working on my Master's thesis at San Jose State University, to examine "Parents" Perceptions of the Impact of an Occupational Therapy Early Intervention Home Program on their Roles and Use of Time."

I am interested in gour opinion of how your child's early intervention program has affected you daily routine and the coles that you play in life (as a pazent, employee, etc.). IT IS THROUG̈ STODIES LÏ̈: THIS THAT OCCUPATIONAL TEERAZISTS LEARN FROM PARENTS "HHAT HORKS AND WHAT DOESN'T FORK" ABOUT A.V EARLY INTERVENTION HOME PROGRAY

It is my hope that the study be a simple and beneficial experience for all involved. First, there is a short survey to fill out, to give me an idea of what your daily schedule is like. Afterwards, I would like to meet with volunteers, at your convenience, to hear about your personal experience. The tape-recorded interview is heard only by myself, and all identities are kept considential.

To take pazt in tisis exciting opootunity. please do not hesitate to contact me at wo:'x ('510) 656-3949, or after hours at home (510) 796-4526.

Thark you for your tine in this worthy endeavor.

$$
\text { sincezely, }
$$

dustine Alcocer, orr 
APPENDIX D

CONSENT FORM 
College of Applied Sciences and Arts - Deportment of Oceupaticnal Therapy
One Washington Square - San Jose, California $95192-0059$

Main Otfice: 408/924-3070. Fieldwork OHice: 408/924-3078 - FAX: 408/924-3088

AGREEMENT TO PARTICIPATE IN RESEARCH

Responsible Investigator: Justine Alcocer, OTR

Title of study: Parents' Perceptions of the Impact of a Home-based Occupational Therapy Early Intervention

Program on their Roles and Use of Time

1) I have been asked to participate in a research study investigating parents' perceptions of their own life roles, daily use of time, and how their child's home-based occupational therapy program might impact roles and time use. 2) I will be asked questions, both in person, and on a brief one-page questionnaire, concerning my daily use of time, my

- roles within a family, work, and social context, and my opinions surrounding the occupational therapy program.

3) The interview will be audio tape-recorded, and conducted at a time and place of my convenience. The interview is expected to take approximately 90 minutes.

4) This study has No anticipated risks. If I feel uncomfortable at any time, I may stop the tape-recording, refrain from answering, or discontinue the study entirely. 5) This study has No anticipated benefits for me. My input in this study may have the long term benefit of aiding professionals in understanding and meeting the needs of families who receive home-based occupational therapy services for their young child with developmental delays. 


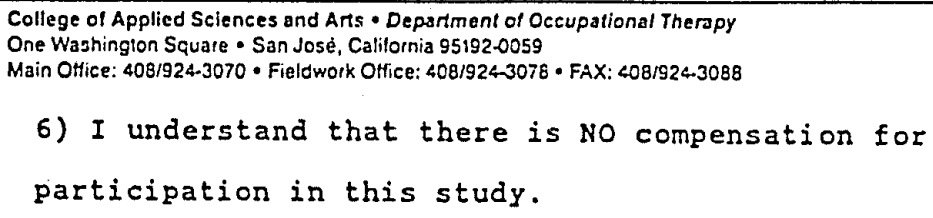


College of Applled Sciences and Ars - Depirtment of Occupallonal Therapy

One Washington Square - San José. Calitornia 95192-0059

Main Otfice: 408/9243070 - Fielicwork Otfice: 408/924-3078 * FaX: 408/9243068

11) I have received a signed and dated copy of this consent form for my file.

MY SIGNATURE (TEAT OF TEE SUBJECT) INDICATES TEAT I EAVE READ

THE INFORMATION PROVIDED ABOVE AND THAT I HAVE AGREED TO

PARTICIPATE IN TEE STODY.

THE RESEARCHER'S SIGNATORE INDICATES AGREEMENT TO INCLUDE TEE

ABOVE NAMED SOBJECT IN THE RESEARCH AND ATTESTS THAT THE

SUBJECT HAS BEEN FULLY INFORMED OE HIS OR HER RIGTTS.

DATE

DATE
SUBJECT'S SIGNATURE

INVESTIGATOR'S SIGNATURE 
APPENDIX E

EXPERIMENTAL BILL OF RIGHTS 
Coltege of Applied Sciences and Arts - Depsrme.t of Occupational Therapy

One Washingten Square - San Jose. Califorma 95192 CC59

Main Ottice: $408 ; 924-3070$ - Fierdwork Otfice: $408 ; 924-3079$ - FAX: 408/924-3088

EXPERIMENTAL SUBJECTS BILL OE RIGHTS

The rights below are the rights of every person who is asked to be in a research study. As an experimental subject I have the following rights:

1) To be told what the study is trying to find out.

2) To be told what will happen to me and whether any of the procedures is different from what would be used in standard practice.

3) To be told about the frequent and/or important risks. side effects, or discomeorts of the things that will happen to me for research purposes.

4) To be told if I can expect any benefit from participating and, if so, what the bezefit might be.

5) To be told the other choices I have and how they may be better of worse than being in the study.

6) To be allowed to ask any questions concerning the study both before agreeing to be involved and during the course of the study.

7) To refuse to participate at all or to change my mind about participation after the study is started. This decision will not affect my right to receive the care I would receive if I were not in the study.

8) To receive a copy of the signed and dated consent form.

9) To be free of pressure when considering whether I wish to agree to be in the study.

If I have other questions I should'ask the researcher. In addition, I may contact the Human subjects Institutional Review Board, which is concerned with protection of volunteess in research projects. I may reach the comnittee by calling: (408) 924-1438 from 8:00 AM to 5:00 PM Monday through Friday, or by writing to the Human subjects

Institutiona! Review Board, San Jose state Oniversity

Eousdation, One Hashingtor. Square, San Jose, CA 95192-0139. 